\title{
A scientific note on the directional accuracy of the waggle dance over the course of a day*
}

\author{
Kathryn E. GARDNER
}

Department of Entomology, Cornell University, Ithaca, NY 14853, USA

Received 21 November 2006 - Revised 18 January 2007 - Accepted 19 January 2007

Waggle dance / dance language / honey bee / Apis / communication

Honey bees communicate information about distance and direction to a food source with a waggle dance (von Frisch, 1993). During the waggle phase see (Tautz et al., 1996), a bee walks forward an angle with respect to vertical while waggling her abdomen. This angle matches, on average, the angle between food source and sun azimuth. For a given food location, there is variation both within dances of the same bee and between different bees.

Lindauer (1961) reported that when the sun is at the zenith (which only occurs in the tropics), dancing either ceases or is disoriented 10 minutes before and after solar noon. No directional information can be communicated when the sun is directly overhead. In temperate regions, colony foraging activity declines around noon, a phenomenon von Frisch (1993) called "noontime laziness". He argued that this effect could not be explained in terms of food profitability, and attributed it to a diurnal periodicity in activity, although this was not directly tested.

An alternative explanation of noontime laziness links these two phenomena: perhaps foragers experience greater difficulty orienting their dances when the sun is higher in the sky, and are less inclined to dance, which in turn reduces foraging activity. This study tests one component of this hypothesis: the effect of the sun's position on the accuracy of the information within the dance.

Three unrelated colonies, A, B, and C, were housed in observation hives (see Seeley, 1995, Chap. 4). Colonies were housed at two locations (A

Corresponding author: K.E. Gardner,

keg28@cornell.edu

Present address: Introductory Biology, 1136 Comstock Hall, Cornell University, Ithaca, NY 14853 , USA.

* Manuscript editor: Stan Schneider and $\mathrm{C}$ were housed together) in Ithaca, NY, USA (W $76^{\circ} 29^{\prime}, \mathrm{N}_{42}^{\circ} 26^{\prime}$ ). The bees were trained (von Frisch, 1993, p. 17) to an artificial feeder of 0.5 to $2.0 \mathrm{M}$ sucrose solution scented with anise oil $(60 \mu \mathrm{L} / \mathrm{L})$. Dances from individually marked forgers were videotaped upon their return to the hive. No part of the sky was visible to the bees as they danced.

The feeder was set up sequentially at 300, 400, and $500 \mathrm{~m}$ from the hive. While certain properties of the dance change with distance (see Gardner et al., 2006), there was no difference in accuracy for these three food-source distances $\left(F_{2,150}=0.17\right.$, $P=0.8439$ ). I recorded 179 dances from 93 bees; each dance had a minimum of 10 waggle phases $(19.7 \pm 8.8$, mean \pm SD). Only one dance per bee per distance was recorded but individual bees were often recorded at more than one distance. All dances were recorded over the period of 12 June 2005 to 21 July 2005, between 08:15 h and 16:15 h EST, which encompasses the summer solstice. On 21 June 2005 the sun reached a maximum altitude of $71^{\circ}$ between 12:01 $\mathrm{h}$ and 12:14 $\mathrm{h}$ EST in Ithaca, NY, USA.

For each dance, I recorded the angle of each waggle phase using a protractor mounted on the monitor with $0^{\circ}$ as straight up. The angle from the hive to the feeders $\left(\theta_{F}\right)$ was measured using a sighting compass (corrected for local declination). The azimuth of the sun $\left(\theta_{S}\right)$ was determined from the Naval Observatory Web Site (U.S. Naval Observatory, 2006). The expected dance angle $\left(\theta_{E}\right)$ is the difference between the sun's azimuth and the direction of the feeder $\left(\theta_{S}-\theta_{F}\right)$. The observed dance angle $\left(\theta_{O}\right)$ is the mean vector bearing of all waggle phases recorded for a dance, calculated with equations found in Fisher (1993). The angular error is defined as the absolute value of $\theta_{O}-\theta_{E}$. The effect of the time of day on angular error was evaluated using 


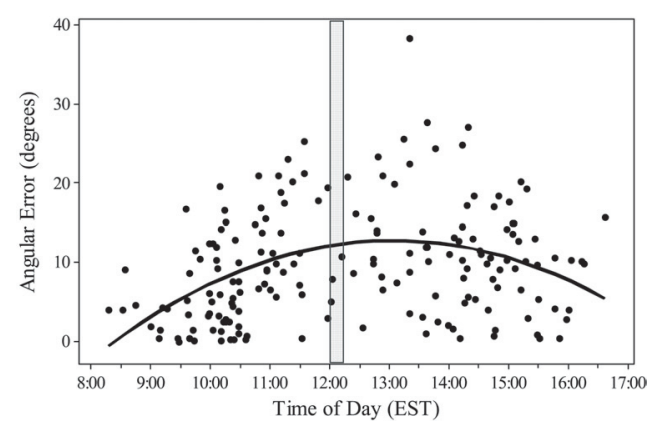

Figure 1. Inaccuracy in the dances of honey bees over the course of a day. The shaded area indicates the time during which the sun is at its highest altitude for the dates that dances were recorded. The angular error is the difference between the mean vector bearing of all waggle phases within a bee's dance ans the expected angle of her dance. Although the highest angular error does not directly correspond with the time when the sun is the highest, the general pattern shows that inaccuracy increases as the sun rises in the sky and then decreases as the sun sets.

a repeated measures model with colony modeled as a fixed effect and time as a covariate with linear and quadratic components using PROC MIXED in SAS (Littell et al., 1996).

For the timeframe of my recordings, the sun reached its maximum altitude of $67.9^{\circ}$ to $71^{\circ}$ between 12:00 $\mathrm{h}$ and 12:15 $\mathrm{h}$ EST. On average, the angular error of dances increased as the sun rose in the sky until about 13:00 $\mathrm{h}$ and then it decreased as the sun began to set (Fig. 1). Based on the fitted quadratic line, the highest angular error within dances occurred at 13:09 h. Both the linear $\left(F_{1,152}=\right.$ $8.66, P=0.0038)$ and quadratic $\left(F_{1,153}=8.93\right.$, $P=0.0033)$ terms in the model were significant. Colony, distance, and associated interactions were not significant $(P>0.50$ for all terms).

The sun is a useful directional reference, in that it is conspicuous and predictable, but it also presents problems since its location (altitude and azimuth) changes throughout the day. Bees compensate by changing their dances according to the direction (azimuth) of the sun, but any affect of the sun's altitude has not been demonstrated. The pattern (Fig. 1) suggests that bees have more difficulty acquiring directional information from the sun when it is higher in the sky. It seems that the angular accuracy of dances is correlated with the altitude of the sun; bees are better able to communicate directional in- formation if the sun is lower in the sky. A question that remains is why the maximum error did not directly correspond to when the sun was at its highest.

Given that von Frisch's (1993) "noontime laziness" is accompanied by a decrease in the accuracy of directional information within dances, the reduction in foraging activity may be adaptive. The dance language presumably evolved to increase colony level foraging efficiency. The bees may reduce their foraging efforts when there is increased difficulty in transmitting accurate information to their nestmates. A key prediction for future studies is that dancing (not just foraging) decreases at midday. Additionally, there may be other activities that distract dancers and foragers from performing their tasks, such as an increased demand for nest maintenance.

\section{ACKNOWLEDGEMENTS}

I would like to thank the undergraduates who assisted me in many ways, A. Koral, B. Schiller, and M. Ryskin. N.W. Calderone, T.D. Seeley and two anonymous reviewers provided helpful comments on the manuscript.

\section{Note scientifique sur la précision directionnelle de la danse frétillante au cours de la journée.}

\section{Zusammenfassung - Eine wissenschaftliche No- tiz zur Richtungsgenauigkeit des Schwänzeltan- zes im Tagesverlauf.}

\section{REFERENCES}

Fisher N.I. (1993) Statistical Analysis of Circular Data, Cambridge University Press, Cambridge, UK.

Frisch K. von (1993) The Dance Language and Orientation of the Bees, Harvard University Press, Cambridge, MA.

Gardner K.E., Seeley T.D., Calderone N.W. (2006) Directional imprecision in the honey bee's waggle dance: Considering adaptive and non-adaptive hypotheses, Entomol. Gener. 29, in press.

Lindauer M. (1961) Communication among Social Bees, Harvard University Press, Cambridge, MA.

Littell R.C., Milliken G.A., Stroup W.W., Wolfinger R.D. (1996) SAS System for Mixed Models, SAS Institute, Inc., Cary, NC.

Seeley T.D. (1995) The Wisdom of the Hive: The Social Physiology of Honey Bee Colonies, Harvard University Press, Cambridge, MA.

Tautz J., Rohrseitz K., Sandeman D.C. (1996) One-strided waggle dance in bees, Nature 382,32 .

U.S. Naval Observatory (2006) Sun or Moon Altitude/Azimuth Table for One Day. Retrieved July 1, 2006 from http: //aa.usno.navy.mil/data/docs/AltAz.html 